\title{
Building Materials And Products
}

DOI 10.36622/VSTU.2020.48.4.003

UDC 539.2

\section{B. M. Kumitsky ${ }^{1}$, N. A. Savrasova ${ }^{2}$, A. V. Nikolaichik ${ }^{3}$, E. S. Aralov ${ }^{4}$ \\ RHEOLOGICAL MODELING OF THE STRESS-STRAIN STATE IN FLAT COMPACTION OF COMPOSITE MATERIALS}

\author{
Voronezh State Technical University ${ }^{1,3,4}$ \\ Russia, Voronezh \\ Military Training and Scientific Center of the Air Force «Air Force \\ Academy named after prof. N. E. Zhukovsky and Yu. A. Gagarin» ${ }^{2}$ \\ Russia, Voronezh
}

\begin{abstract}
${ }^{1}$ PhD in Physics and Mathematics, Assoc. Prof. of the Dept. of Heat and Gas Supply and Oil and Gas Business, tel.: +7-999-401-60-87, e-mail: boris-kum@mail.ru

${ }^{2}$ PhD in Physico-mathematical sciences, Assoc. Prof. of the Dept. of Physics and Chemistry, tel.: +7-951-872-94-25,e-mail: savrasova-nataly@mail.ru

${ }^{3}$ PhD in Engineering, Assoc. Prof. of the Dept. of Heat and Gas Supply and Oil and Gas Business, tel.: +7(473) 271-53-21, e-mail: teplosnab_kaf@vgasu.vrn.ru

${ }^{4}$ PhD student of the Dept. of Heat and Gas Supply and Oil and Gas Business, tel.: +7-960-125-29-96,e-mail: vgtu.aralov@yandex.ru
\end{abstract}

\begin{abstract}
Statement of the problem. The article investigates the deformation behavior of a composite material in the process of its flat pressing. To solve this problem, a rheological model is proposed, which is based on the phenomena occurring in a viscous (Newtonian) incompressible fluid, which occupies the volume between two absolutely rigid parallel planes of finite dimensions of rectangular shape approaching at a low speed. Within the framework of mechanics of a continuous medium under conditions of a plane deformed state, the problem is solved in two dimensions about a slow flow in the absence of volume forces and inertial effects. In this case, the solution of the equation of motion with continuity conditions is reduced to the well-known Laplace equation. In addition, on the basis of the model of linear viscoelasticity and uniaxial stress state, an attempt has been made to describe the relaxation phenomena occurring in the solidifying composite at the end of the active pressing process.

Results and Conclusions. Analytical dependences of the power parameters of the stress-strain state of the compressed composite are obtained; relations for the kinematic characteristics of the pressing process are obtained; an expression is obtained for the relaxation of stresses during the technological holding of the material under pressure after the end of active pressing. The results of the study make it possible to experimentally determine the numerical values of the dynamic coefficient of viscosity and stress relaxation time, which are important characteristics in controlling the pressing processes.
\end{abstract}

Keywords: relaxation, rheological model, viscosity, Newtonian fluid, compression.

Introduction. In all branches of production, the requirements for the quality of products using parts and assemblies made of composite materials are being currently tightened. 
This is due to the fact that composites have a range of unique physical, mechanical and operational characteristics and properties $[2,8,10,13]$.

A composite is a structural material consisting of several components: a matrix (binding material) and a filler (reinforcing material) which reinforces its elements in the form of threads, fibers, particles, etc. The mechanical behavior of composites is defined by the ratio of the properties of the reinforcing elements and the matrix as well as the strength of the bond between them $[9,10]$.

Methods for the production of composite materials and methods for studying the stress-strain in the process of pressing products from composites are still an urgent issue of continuum mechanics. Recently a number of mathematical models have been developed that describe the processes taking place under the conditions of deformation of composites particularly during their flat pressing $[2,4,6,9,10,14]$. A mathematical model is set forth $[9,10,14]$ which describes the phenomena taking place in a viscous incompressible fluid that occupies the volume in a layer between approaching parallel plates. The kinematic parameters obtained in this case make it possible to control the pressing process of plywood and other laminated materials. An identical model based on the motion of a viscous fluid located between converging flat circular plates of finite radius was set forth in $[3,15]$. An expression is obtained for the total drag force that ensures the fluid flow at a given speed. In studies [10, 19], a rheological model of flat pressing of composite materials was developed, based on Prandtl's problems of plastic flow in two dimensions of a plastic material in the absence of elastic deformations. In this case, the von Mises plasticity condition and the associated flow law are employed. Expressions are obtained for the components of the velocities, the flow of the pressed material along the plane of the stamp proportional to a specific speed of closing the plates. In this case, the deforming stresses do not depend on this parameter which contradicts the conclusions [7, 22].

A mathematical model relying on the fundamental laws of conservation of mass, momentum and energy, within the framework of the mechanics of a deformed solid under the conditions of wood pressing considering anisotropy was set forth in [6]. The results of modeling the process of flat pressing of plates as well as waste wood and thermoplastics [13, 16] where the dependences of temperature, degree of solidification, normal and tangential stresses along the thickness of the plates are obtained. Some recommendations on the problem of pressing are suggested. The above analysis as well as other known models [1, 2, 5, 17-21] shows that most of them describe the deformation behavior of the binder, and they do not apply to the overall material. In addition, some of the suggested models are based on the provisions of the theory of plasticity which do not completely describe the deformation behavior of composite materials. 
The objective of the suggested research is to develop a physical and mathematical model that within the framework of continuum mechanics would describe the rheological properties of the composite during pressing and make it possible to obtain the values of the kinematic parameters and the force characteristics of the stress-strain. On top of that, it is required to qualitatively assess the relaxation phenomena occurring following the end of the composite pressing process when the internal stresses during deformation are redistributed.

1. Statement of the pressing problem and solution methods. So, let the space between two rigid rough parallel plates approaching each other at a constant low speed $v_{0}$ be filled with a viscous composite material whose the rheological properties correspond to the model of an ideally viscous medium. It can be represented by some damper shown in Fig. 1.

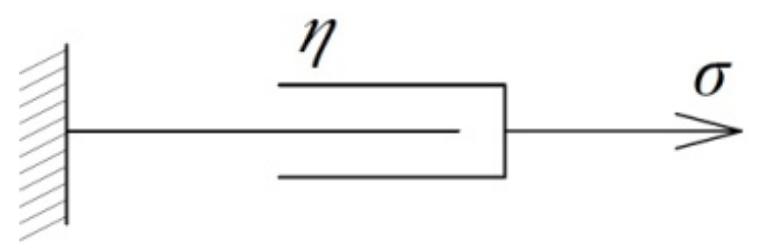

Fig. 1. Scheme of an ideally viscous Newtonian medium with the viscosity $\eta$ and mechanical stress $\sigma$

A schematic diagram of the deformation of the medium is presented in Fig. 2 [10].

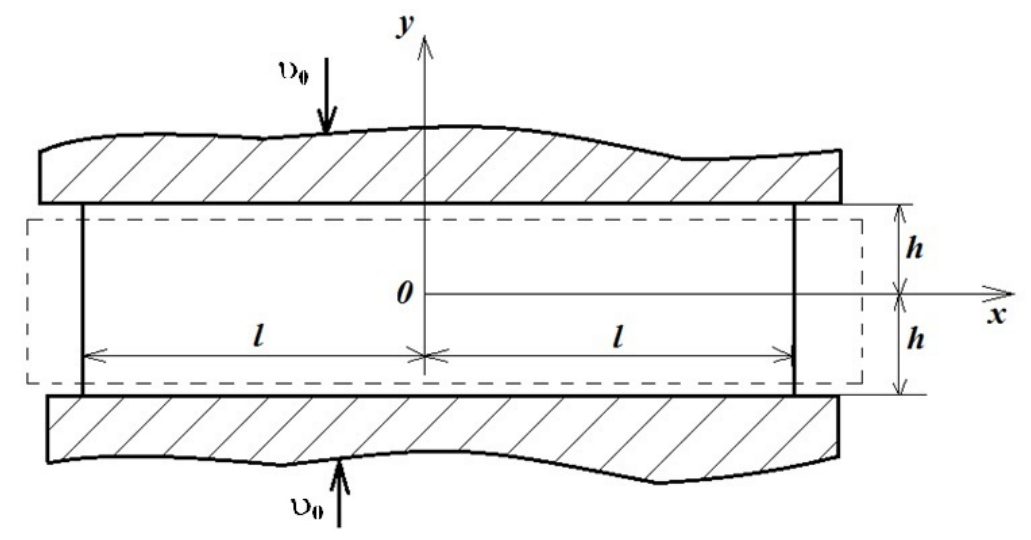

Fig. 2. Compression of a thin layer of a composite approaching with a constant speed $v_{0}$ with parallel plates $(-l<x<l ; y= \pm h)[10]$

It is necessary to evaluate the stress-strain of the composite under conditions of flat pressing, the velocity field as well as the pressing force to ensure a specific speed of plate closing. Let us assume that the flow plane is determined by the coordinates $x, y$ (Fig. 2), and all defor- 
mation parameters do not depend on $z$ [10]. For the case of plane deformation, the equilibrium equations for an incompressible fluid take the following form:

$$
\frac{d v_{x}}{d x}+\frac{d v_{y}}{d y}=0
$$

where $v_{x}$ and $v_{y}$ are components of the velocity vector $\vec{v}$ of particles of the medium in direction to the axes $x$ and $y$ respectively.

Considering this dependence, in the absence of volume forces and inertial effects the NavierStokes equations can be written in the following form [7, 22]:

$$
\begin{aligned}
& -\frac{1}{y} \cdot \frac{d P}{d x}+\frac{d^{2} v_{x}}{d x^{2}}+\frac{d^{2} v_{x}}{d y^{2}}=0 \\
& -\frac{1}{\eta} \cdot \frac{d P}{d y}+\frac{d^{2} v_{y}}{d x^{2}}+\frac{d^{2} v_{y}}{d y^{2}}=0
\end{aligned}
$$

where $P$ is a hydrostatic pressure, $\eta$ is the coefficient of the viscosity of the medium.

The joint solution of equations (1) - (3) leads to the well-known Laplace equation for pressure:

$$
\frac{d^{2} P}{d x^{2}}+\frac{d^{2} P}{d y^{2}}=0 .
$$

The ratios (1) - (4) should meet the following boundary conditions:

$$
\begin{gathered}
v_{x}=0,-l \leq x \leq l, \text { when } y= \pm h, \\
v_{y}= \pm v_{0},-l \leq x \leq l, \text { when } y= \pm h .
\end{gathered}
$$

Due to the symmetry of the problem, it should be an odd function of the $x$ coordinate:

$$
v_{x}(-x)=-v_{x}(x)
$$

The solution of equation (4) is satisfied by the second-degree polynomial [9]:

$$
P=\frac{1}{2} k y^{2}-\frac{1}{2} k x^{2}+c,
$$

where $k$ and $c$ are constants.

Since the pressure $P$ does not depend on the signs of $x$ or $y$, the solution (7) cannot include terms in the first degree. Also, due to the oddness of the function, it cannot contain members with $x^{2}$. Therefore, the solution to equation (2) should be sought for the case $\frac{d^{2} v_{x}}{d x^{2}}=0$. Using this condition and expression (7), equation (2) will be written as:

$$
\frac{d v_{x}}{d^{2} y^{2}}=-\frac{k x}{\eta},
$$


with the following ratio as its solution:

$$
v_{x}=-\frac{1}{2} \cdot \frac{k x y^{2}}{\eta}+y f(x)+\phi(x)
$$

where $f(x)$ and $\phi(x)$ are unknown functions of $x$ where the boundary conditions (5) require that $f(x)=0$ and $\phi(x)=\frac{k x h^{2}}{2 \eta}[9,10]$.

For this case equation (9) is as follows:

$$
v_{x}=\frac{k x\left(h^{2}-y^{2}\right)}{2 \eta}
$$

Inserting it into the continuity equation (1), we get

$$
\frac{d v_{y}}{d y}=-\frac{k\left(h^{2}-y^{2}\right)}{2 \eta} .
$$

Integrating the latter, we get

$$
v_{x}=\frac{k y^{2}\left(3 h^{2}-y^{2}\right)}{6 \eta}+\psi(x),
$$

where $\psi$ is an unknown function of $x$ which according to the boundary conditions (6) is zero and

$$
k=\frac{3 \eta v_{0}}{h^{2}} \text {. }
$$

Considering (13) we get the expressions for the components of the velocity of a viscous liquid and pressure distribution:

$$
\begin{aligned}
& v_{x}=-\frac{3 v_{0} x\left(h^{2}-y^{2}\right)}{2 h^{3}}, \\
& v_{y}=\frac{v_{0} y\left(y^{2}-3 h^{2}\right)}{2 h^{3}}, \\
& P=\frac{3 \eta v_{0}\left(y^{2}-x^{2}\right)}{2 h^{3}}+c .
\end{aligned}
$$

The constant $c$ can be found from the conditions at the boundaries: at $x= \pm l$ and $y= \pm h$ where in practical cases the liquid is squeezed out from under the plates at atmospheric pressure $P=P_{0}$. Then the expression

$$
P=\frac{3 \eta v_{0}\left(y^{2}-h^{2}-x^{2}+l^{2}\right)}{3 h^{3}}+P_{0}
$$

which is an exact solution to equation (4), is valid for the entire length of the lines $x= \pm l$. It is seen that the pressure in the layer between the plates is distributed according to the parabo-lic law. 
Substituting values (14), (15) and (17) into the known expressions [7]

$$
\begin{gathered}
\sigma_{x}=2 \eta v_{x}-P, \\
\sigma_{y}=2 \eta v_{y}-P, \\
\tau_{x y}=\eta \frac{d v_{x}}{d y},
\end{gathered}
$$

we obtain the following expressions for the components of stresses arising during plane deformation of the investigated fluid in coordinates $x, y$ :

$$
\begin{gathered}
\sigma_{x}=3 \eta \frac{v_{0}\left[3\left(h^{2}-y^{2}\right)+x^{2}-l^{2}\right]}{2 h^{3}}, \\
\sigma_{y}=\frac{3}{2} \frac{\eta v_{0}}{h^{3}}\left[y^{2}-h^{2}+x^{2}-l^{2}\right], \\
\tau_{x y}=-\frac{3 \eta v_{0} x y}{h^{3}} .
\end{gathered}
$$

The effort $F$ applied to both planes is as follows:

$$
F=-2 h \int_{0}^{l} \sigma_{y} d x=\frac{2 \eta v_{0} l^{3}}{h^{3}} .
$$

The last expression can be employed in viscometry for the practical determination of the viscosity coefficient $\eta$ of the molded material of the composite at the known values $F$ and $v_{0}$. Expression (11) allows an at least qualitative plan of velocities in the form of streamlines, tangents to which at each point coincide with the direction of the velocity of the particles of the viscous composite (Fig. 3).

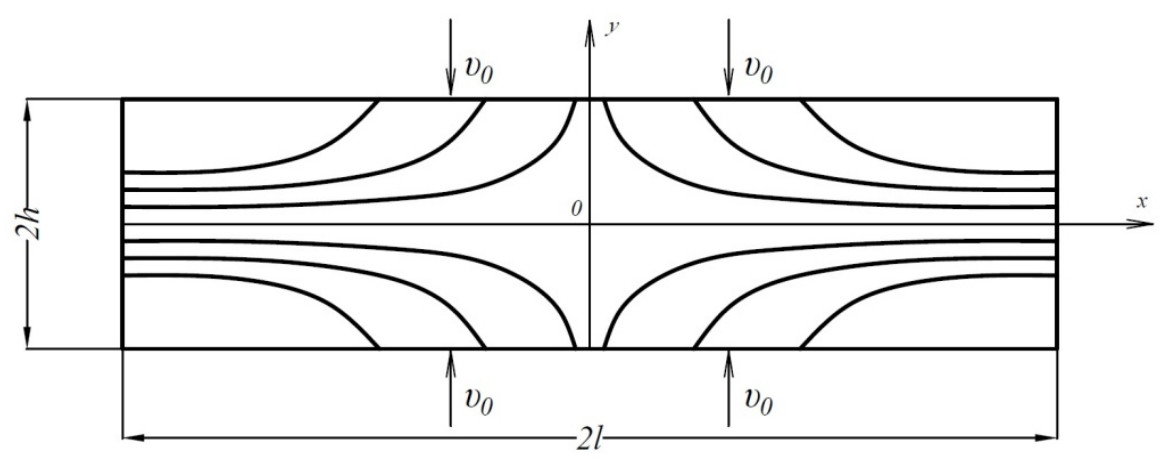

Fig. 3. Scheme of the plan of velocities (streamlines) of particles of the composite mass in the slip plane

Assuming that the pressing process proceeds at a constant load, it is possible to determine the time when the composite thickness becomes equal to the specified one. Let us assume that the lower press plate is stationary, while the upper press is displaced by the total action of gravity 
of the plate itself and some additional load. Denoting the total weight through $Q$ and the speed of its movement, we have the differential equation of motion of the loaded upper plate $v=-\frac{d h}{d t}$, we have a differential equation of the pressure of the loaded upper plate:

$$
\frac{Q}{q} \cdot \frac{d v}{d t}=Q+\frac{2 \eta l^{3}}{h^{3}} \cdot \frac{d h}{d t}
$$

whose integration leads to the following expression:

$$
\frac{Q}{q} v=Q t-\frac{\eta l^{3}}{h^{2}}+c .
$$

The constant $c$ in (23) will be found using the initial conditions:

$$
\text { at } t=0 \quad v=0, h=h_{0} .
$$

Then for the velocity of the loaded plate we get the expression

$$
v=g t-\frac{q \eta l^{3}}{Q}\left(\frac{1}{h^{2}}-\frac{1}{h_{0}^{2}}\right) \text {. }
$$

If we assume that the velocity $v$ is low, using the last equation we obtain the formula for the dependence of the layer compression time on its thickness:

$$
t=\frac{\eta l^{3}}{Q}\left(\frac{1}{h^{2}}-\frac{1}{h_{0}^{2}}\right) .
$$

Just as (21), expression (24) can serve for an approximate calculation of the viscosity coefficient of a substance.

2. Description of the relaxation processes of solidifying composites. The technology for the production of composite materials provides for holding the pressed sheets under pressure in order to relieve internal stresses, harden the binder, and level out the temperature and humidity fields.

Internal stresses are a consequence of incomplete relaxation processes and are the major cause of buckling of the sheet composite. This explains the urgency of the problem of studying relaxation processes in composite materials under stress-strain conditions.

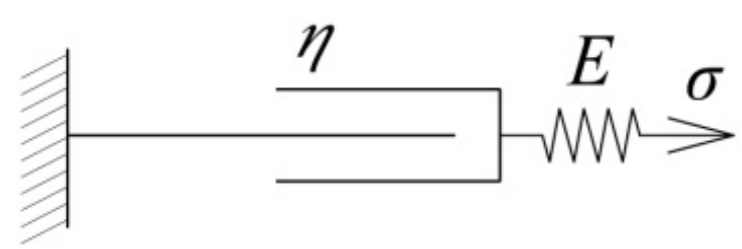

Fig. 4. Model of a Maxwell viscoelastic medium with an elastic modulus $E$ and a viscosity coefficient $\eta$ 
The pressing speed, including holding under pressure, depends on the rate of relaxation of internal stresses. In materials such as carbon plastics [10-12], the change in internal stresses proceeds in accordance with the model of a viscoelastic body consisting of a spring and a damper connected in series (Fig. 4).

If a material subjected to deformation under the influence of a load is left under a load so that no further change in its shape takes place and the total deformation remains constant, the load will decrease over time.

Indeed, during the deformation of the material corresponding to the model (Fig. 4), the stress in the spring and the damper will be identical. If the deformations are designated $\varepsilon_{1}$ and $\varepsilon_{2}$ respectively,

$$
\varepsilon_{1}=\frac{\sigma}{E} ; \frac{d \varepsilon_{2}}{d t}=\frac{\sigma}{\eta}
$$

and the complete deformation, which equals

$$
\varepsilon=\varepsilon_{1}+\varepsilon_{2},
$$

meets the condition:

$$
\frac{d \varepsilon}{d t}=\frac{1}{E} \cdot \frac{d \sigma}{d t}+\frac{\sigma}{\eta}
$$

If the deformation $\varepsilon_{0}$ is imparted to the system instantly at a moment $t=0$, at a time $t$ the stress will change in compliance with (25):

$$
\sigma=E \varepsilon_{0}\left(1-e^{-\frac{E}{\eta} t}\right)
$$

Here $\tau=\frac{\eta}{E}$ is the stress relaxation time when the stresses decrease by a factor of $e$. Depending on the type of composite material, stress relaxation lasts from several minutes to several months. As already mentioned, the speed of pressing depends on the speed of relaxation, the relaxation time becomes an important parameter for predicting the quality of products.

Conclusions. According to the results of the study, the following conclusions can be made:

1. A rheological model has been set forth that describes the properties of a composite mass in the process of flat pressing.

2. Analytical dependences of the parameters of the stress-strain state are obtained: the components of stress and pressing pressure.

3. Analytical expressions have been obtained for the components of the flow velocity of the pressed material enabling a plan of velocities to be designed graphically. 
4. An expression for the pressing time has been obtained allowing one to experimentally determine the viscosity coefficient of a deformable medium.

5. Based on a linear viscoelastic model within the framework of uniaxial deformation, an analysis of changes in internal stresses is performed.

\section{References}

1. Aleksandrov S. E., Baranova I. D., Mishuris G. Szhatie vyazkoplasticheskogo sloya mezhdu sherokhovatymi parallel'nymi plitami [Compression of the viscoplastic layer between rough parallel plates]. Izv. RAN. MTT, 2008, no. 6, pp. 33-39.

2. Antsiferov V. N., Perel'man V. E. Mekhanika protsessov pressovaniya poroshkovykh i kompozitsionnykh materialov [Mechanics of pressing processes of powder and composite materials]. Moscow, Graal' Publ., 2001. 631 p.

3. Aristov S. N., Knyazev D. V. Techeniya vyazkoi zhidkosti mezhdu podvizhnymi parallel'nymi ploskostyami [Flows of a viscous liquid between mobile parallel planes]. Izvestiya Rossiiskoi Akademii nauk. Mekhanika zhidkosti i gaza, 2012, no. 4, pp. 55-61.

4. Bakhteev O. A., Lysikov A. V., Mikheev E. N. e.a. Matematicheskoe modelirovanie protsessa pressovaniya poroshka dioksida urana pri izgotovlenii tabletok yadernogo topliva [Mathematical modeling of the process of pressing uranium dioxide powder in the manufacture of nuclear fuel tablets]. Vestnik natsio-nal'nogo issledovatel'skogo yadernogo universiteta «MIFI», 2014, vol. 3, no. 6, pp. 618-622.

5. Burago N. G., Nikitin I. S. Matematicheskaya model' dlya rascheta pressovaniya i spekaniya poroshkovykh materialov [Mathematical model for calculating pressing and sintering of powder materials]. Izdatel'stvo Yuzhnogo federal'nogo universiteta Rostov-na-Donu; Taganrog, 2017. Pp. 21—27.

6. Dornyak O. R. Matematicheskoe modelirovanie protsessa pressovaniya drevesiny v razlichnykh napravleniyakh mekhanicheskoi anizotropii [Mathematical modeling of wood Pressing process in various directions of mechanical anisotropy]. Izvestiya vuzov. Severo-Kavkazskii region. Tekhnicheskie nauki. Spets. vypusk "Kompozitsionnye materialy", 2005, pp. 85-92.

7. Eger Dzh. K. Uprugost', prochnost' i tekuchest' [Elasticity, strength and fluidity]. Moscow, MAShGIZ Publ., 1961. $172 \mathrm{p}$

8. Kozlov G. V., Zaikov G. E., Stoyanov O. V., Kochnev A. M. Dispersno-napolnennye polimernye nanokompozity [Dispersed-filled polymer nanocomposites]. Kazan, KNITU Publ., 2012. 125 p.

9. Kumitskii B. M., Savrasova N. A., Kantieva E. V. Matematicheskoe modelirovanie protsessa skleivaniya drevesnogo shpona $\mathrm{v}$ usloviyakh ploskogo pressovaniya fanery [Mathematical modeling of the process of gluing wood veneer in the conditions of flat pressing of plywood]. Lesotekhnicheskii zhurnal, 2018, vol. 8, no. 2 (30), pp. 204-212.

10. Kumitskii B. M., Savrasova N. A., Mel'kumov V. N., Aralov E. S. Matematicheskoe modelirovanie kholodnogo pressovaniya listovogo kompozita [Mathematical modeling of cold pressing of sheet composite]. Nauchnyi zhurnal stroitel'stva i arkhitektury, 2020, no. 1 (57), pp. 42-50.

11. Luk'yanov N. A., Stepanov M. A., Korolev A. A. Reologicheskaya model' i uravnenie techeniya uprugovyazko-plastichnoi massy [Rheological model and equation of elastic-visco-plastic mass flow]. Vestnik MGSU, 2013, no. 5, pp. 43-48. 
12. Magomedov G. O., Zhuravlev A. A., Shevyakova T. A., Plotnikova I. V. Reologicheskaya model' deformatsionnogo povedeniya sakharnogo testa $\mathrm{V}$ usloviyakh od-noosnogo szhatiya [Rheological model of deformation behavior of sugar dough under uniaxial compression]. Vestnik Voronezhskogo gosudarstvennogo universiteta inzhenernykh tekhnologii, 2014, no. 4, pp. 110-114.

13. Plotnikov N. P., Plotnikova G. P. Sovershenstvovanie tekhnologii proizvodstva drevesnoplitnykh materialov. [Improving the technology of production of wood-plate materials]. Novosibirsk, NP «SibAK», 2013. $112 \mathrm{p}$.

14. Savrasova N. A., Agapov A. D., Kumitskii B. M. [Mathematical modeling of flat pressing of layered plastics]. Sovremennye problemy teorii mashin [Modern problems of theory of machines]. Novokuznetsk, Izd-vo NITsMS, 2018, pp. 50-55.

15. Khaneft A. V. Osnovy mekhaniki sploshnykh sred v primerakh i zadachakh. Ch. 1. Gidrodinamika : uchebnoe posobie [Fundamentals of continuum mechanics in examples and problems. Part 1. Hydrodynamics : textbook]. Kemerovo, GOU VPO Kemerovskii gos. un-t Publ., 2010. 97 p.

16. Chubinskii A. N., Sergeevichev V. V. Modelirovanie protsessov skleivaniya drevesnykh materialov [Modeling of gluing processes of wood materials]. Saint Petersburg, 2007. 176 p.

17. Adams M. J., Briscoe B. J., Corfield G. M. An analysis of the plane-strain compression of viscoplastic materials. Trans. ASME. J. Appl. Mech, 1997, vol. 64, pp. 420-424.

18. Bunoiu R., Kesavan S. Asymtotic behavior of a Bingham fluid in thin layers. J. Math. Anal, appl., 2004, 293 (2), pp. 405-418.

19. Prandtl L. Anwendungsbeispiele zu einem Henckyschen Salz uber das plastische Gleichgewicht. Zangew. Math. Mech, 1923, bd. 3, pp. 401-406.

20. Sherwood J. D., Durban D. Squeeze flow of a power-law viscoplastic solid. J. Non-Newton. Fluid Mech, 1996, vol. 62, no. 1, pp. 35-54.

21. Wilson S. D. R. Squeezing flow of a Bingham material, J. Non-Newtonian Fluid Mech, 1993, no. 47, pp. $211-219$.

22. Zhu H., Kim Y. D., Kee D. D. Non-Newtonian fluids with stress. Journal of Non-Newtonian Fluid Mechanics, 2005, vol. 129, no. 3, pp. 177-181. 